\title{
Evaluating professorial halos
}

$\mathrm{E}$ ven the notion that there might come a day when a Canadian medical school might issue a press release hailing an improved rating on a scorecard designed to measure conflicts of interest between faculty and industry, as several American institutions have over the past month, seems unfathomable.

That a Canadian school might someday issue a press release saying that a "poor grade" received on such a scorecard was the impetus to the introduction of a new conflict of interest policy, as happened with the University of Illinois College of Medicine in 2010 (www.medicine.uic.edu/research /archives/pharmfreerating/), is beyond comprehension.

But such appears to have been the impact of the American Medical Student Association's (AMSA) PharmFree Scorecard, which takes medical faculty to task for meals and other gifts like exotic trips paid by industry, as well as speakers' fees and a host of other paid consulting relationships that have developed through the years. Since its creation in 2007, the scorecard, along with a raft of national policies such as the Association of American Medical Colleges' call for a zero-tolerance approach to industry handouts (www.cmaj.ca /lookup/doi/10.1503/cmaj.080780), has resulted in what many have called a sea change in American medical education.

Perhaps no more evidence for that proposition exists than the most recent findings of the AMSA scorecard, in which 102 (67\%) of America's 152 medical schools received grades of A or B in the 2011-2012 evaluation of their conflict-of-interest policies, compared with 79 in 2010-2011 (www.amsa scorecard.org). That's 23 medical schools stiffening conflict-of-interest policies in a single year.

By contrast, Canadian students have developed no such measure of the goodies received by their instructors, while Canadian medical bodies have not unveiled national policies similar to

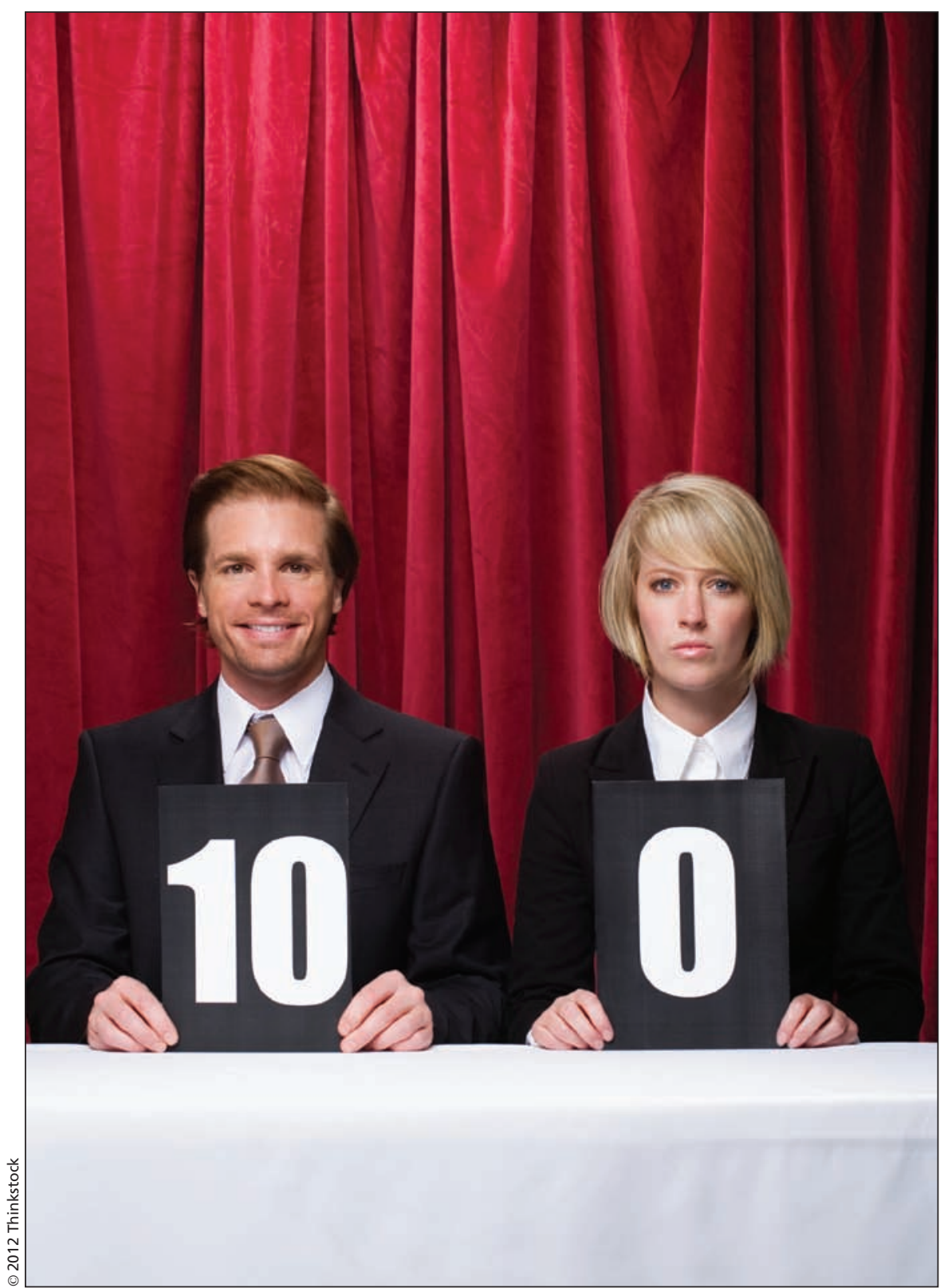

While American medical students are evaluating the extent of their professors' conflicts of interest with industry, Canadian students haven't contemplated similar assessments of a faculty's willingness to accept handouts north of the 49th parallel.

that of the Association of American Medical Colleges' call for a strict crackdown on industry handouts. Nor has there been any indication that any of Canada's 17 medical schools are tightening the noose on cozy relationships with industry.

Although there's widespread varia- tion in policies that Canadian medical schools have toward pharmaceutical and medical devices handed out by industry for medical education and, in some cases, seemingly no policies at all, administrators have long argued that such restrictive measures aren't needed north of the 49th parallel 
because the level of abuse is much lower (www.cmaj.ca/lookup/doi/10.1503 /cmaj.081008).

AMSA's scorecard was created in 2007 because of student concerns that inadequate conflict of interest policies were having a detrimental impact on their education, says Lee Shapley, a medical student at Oregon Health and Science University and director of the PharmFree scorecard.

It assesses conflict of interest policies in six domains:

"• 1 . Gifts and individual financial relationships with industry

1A. Gifts (including meals)

1B. Consulting relationships (excluding scientific research and speaking)

1C. Industry-funded speaking relationships

1D. Disclosure

- 2. Pharmaceutical Samples

- 3. Purchasing \& Formularies

- 4. Industry Sales Representatives

- 5. Education

5A. On-site Educational Activities 5B. Compensation for Travel or Attendance at Off-site Lectures \& Meetings

5C. Industry Support for Scholarships \& Funds for Trainees

5D. Medical school curriculum

\section{- 6. Enforcement."}

The scorecard does not assess institutional conflict-of-interest policies related to research, as that's "outside the scope" of the student association, Shapley says.

There's no question that the scorecard has been a contributory factor in the tightening of conflict-of-interest policies, Shapley adds, noting that the number of American medical schools receiving A or B grades on their policies has increased to about $70 \%$ from roughly $15 \%$ in 2008.

Students are ideally positioned to evaluate conflict-of-interest policies at medical schools, Shapley says. "Being students, we're somewhere in between being physicians and the public. As opposed to being physicians who are wholly on one side of the system, we're somewhere in the middle. We're a little bit more like patients who are consuming medical care."

But no such scorecard or evaluation system for Canadian medical schools is being contemplated by Canadian students, says Matthew Tenenbaum, spokesperson for the Canadian Federation of Medical Students (CFMS).

Tenenbaum adds that the federation approved a position paper in September 2011 putting forward recommendations for CFMS member schools concerning institute interactions with industry (www .cfms.org/attachments/article/163/cfms _industry_funding_working_group_paper .pdf). Those recommendations included a call for schools to educate students about appropriate relationships with industry, to monitor industry involvement in educational and extracurricular activities, and require faculty to disclose conflicts of interest. The students also recommended that their own societies refrain from accepting gifts or funding from pharmaceutical companies.

For their part, medical education administrators say they are not averse to seeing Canadian schools evaluated for their conflict-of-interest policies.

Provided it is announced in advance so schools developing or revising policies have an opportunity to get everything in order, "a scorecard system is in line with the notion that the more public and the more transparent you make the information relating to people's conflicts, both the fewer the conflicts are and the easier they are to manage," says Irving Gold, vice president of government relations and external affairs at the Association of Faculties of Medicine of Canada.

But Gold and others say there really isn't a need for such evaluation measures in Canada.
"I think there's enough pressure the institutions feel already to develop good COI [conflict-of-interest] policies. I don't think it would actually increase the pressure," says Dr. Verna Yiu, interim dean of the faculty of medicine and dentistry at University of Alberta in Edmonton.

"All of the issues that the US is battling with in terms of COI we face as well, but it's of a different nature," Gold adds. "I think in some ways Canada has an environment where some of the more egregious conflict of interest violations that have happened in the United States really couldn't happen here."

Others disagree.

Having a Canadian equivalent of the AMSA scorecard would certainly be of value, says Dr. Joel Lexchin, professor of health policy and management at York University in Toronto, Ontario.

"For AMSA, one of the things that they've found is that schools that score low are sometimes embarrassed and want to know why they scored as low as they did and what they can do to improve their scores. So I think that having a tool that would compare the medical schools in Canada might serve as a stimulus for some of them to try and develop better policies," says Lexchin, who's undertaking a comparison of Canadian medical school conflict-of-interest policies using a modified version of the AMSA scorecard.

Lexchin surmises that Canadian students have not leaped into the evaluation fray because they lack the resources, but hopes they have an interest in doing so. "They're the ones who are, in some respects, being directly affected by the policies that the schools have, so it would be nice to see them be interested in how those policies are affecting their medical education." Andrea Hill, Ottawa, Ont.

CMAJ 2012. DOI:10.1503/cmaj.109-4189 